\title{
Investor Sentiment, Market Timing, and Futures Returns
}

\author{
Changyun Wang* \\ Department of Finance and Accounting \\ National University of Singapore
}

September 2000

\footnotetext{
* Correspondence address: Department of Finance and Accounting, School of Business, National University of Singapore, 10 Kent Ridge Crescent, Singapore 119260, Tel: +65 874-4555, Fax: +65 779-2083, Email: fbawcy@nus.edu.sg. The author thinks an anonymous referee for invaluable comments and suggestions. The financial support from the NUS Academic Research Fund is greatly acknowledged.
} 


\title{
Investor Sentiment, Market Timing, and Futures Returns
}

\begin{abstract}
Investor sentiment index based on actual trader positions is useful for forecasting $\mathrm{S} \& \mathrm{P}$ 500 index futures returns. We find that large speculator sentiment is a price continuation indicator, whereas large hedger sentiment is a weak contrary indicator. Small trader sentiment does not forecast returns. We show that extreme levels and the combination of extreme levels of sentiments of the two types of large traders may provide a more reliable tool for forecasting. Our result suggests that large speculators may be associated with superior forecasting ability, large hedgers behave like positive feedback traders, and small traders are liquidity traders. Our further empirical evidence is broadly supportive of this contention.
\end{abstract}


Commitments of Traders (COT) reports that have been published periodically by the CFTC since early 1980s detail positions taken by categorized traders in US futures markets. The CFTC annually classifies the reportable positions as either commercial or noncommercial. Traders who take commercial positions to hedge a specific risk are referred to as large hedgers, those who take noncommercial positions for reasons other than hedging are referred to as large speculators, and traders whose positions do not exceed the CFTC's reporting threshold are referred to as small traders. ${ }^{1}$ Based on net positions by a type of traders, the investor sentiment index (commonly termed as the COT index) is often promoted as a useful timing indicator. Compared to other bullish sentiment indices that are based on analysts' opinions, the COT index may be more closely related to private information in futures markets. Briese (1994) wrote:

The Commitments reports can be followed much like SEC insider-transactions numbers to spot special situation ... Commercials are typically value buyers. When their net buying is near its historical top, it is a tip-off that they think bargains are available. When their net position reaches its lower historical boundary, it usually means that they think tulip-mania has griped a market.

Arnold (1995) stated:

Learn why an understanding of open interest is crucial in futures trading. Are there really insiders in futures markets? And if so, how you benefit by examining their positions? You'll learn about my unique COT index and how I use it to find high profitability trades.

Does investor sentiment based on trader positions forecast future market movements in futures markets? How do traders forecast market movements? What makes traders bullish or

\footnotetext{
${ }^{1}$ The CFTC's reporting threshold is adjustable, and differs across contract markets. As of the end of 1999, the reporting threshold for the S\&P500 index futures was 600 contracts.
} 
bearish? How do changes in sentiment affect futures prices? Which type of traders may be better informed in the market? This article attempts to answer these questions.

We find that the sentiments of both large speculators and large hedgers are useful markettiming indicators, but they provide opposite forecasts. Large speculator sentiment is a price continuation indicator. Contrary to popular beliefs, large hedger sentiment is a (weak) contrary indicator. $^{2}$ Small trader sentiment hardly forecasts future market movements. We proceed to investigate various timing strategies based on investor sentiment, and find that extreme levels and the combination of extreme levels of sentiments of large speculators and large hedgers provide a more reliable tool for forecasting. The evidence may suggest that large speculators as a whole are associated with superior forecasting ability, large hedgers behave like positive feedback traders who often overreact to nonfundamental information, and small traders are liquidity traders whose trading motives reflect liquidity needs. Thus, that the informativeness of trades differs across trader types may explain the usefulness of sentiment by type of trader for forecasting. To substantiate this claim and check the robustness of our results, we further investigate the relation between future returns and past returns, the relation between the level of sentiment by type of trader and past returns, the relation between changes in sentiment by type of trader, past returns and past volatility, and the relation between absolute changes in sentiment by type of trader and futures volatility. We show that future returns are not predicted by past returns in the futures market, and the investor sentiment does not appear to be significantly affected by past returns. However, there exists a negative and statistically significant relation between small

\footnotetext{
${ }^{2}$ Market analysts or newsletter writers believed that hedgers often sit on the right side of a market, especially in the S\&P 500 index futures market. For example, Briese (1994, p.20) stated: "(I)f you follow only one market, the S\&P 500 would be a good choice...They (commercials) have shown an uncanny knack for spotting opportunities in the S\&P. Historically, a bearish signal has been generated whenever commercials held more short than long contracts."
} 
trader sentiment and past volatility, and a positive relation between absolute changes in hedger sentiment and futures volatility. Generally consistent with standard market microstructure models and noise trading theories, our empirical evidence supports our conjecture on the informativeness of trades by type of trader. The differential informativeness of trades by type of trader thus explains the usefulness of the sentiment by type of trader for predicting the S\&P 500 futures returns.

\section{Literature}

Standard market microstructure theories, for example, Pfleiderer (1984), Kyle (1985), Admati and Pfleiderer (1988), classified traders into two groups: informed traders and liquidity traders. Informed traders receive an informative signal about fundamentals, and their trading moves asset prices in the direction of fundamentals. Liquidity traders are uninformed, passive, and motivated to trade for liquidity needs. These liquidity needs include idiosyncratic wealth shocks, tax planning, risk exposure adjustments, etc. The effect of liquidity demand shocks on prices is counteracted by informed trading, and therefore, liquidity traders do not systematically move prices. However, De Long, Shleifer, Summers, and Waldmann (1989, 1990a, 1990b) argued that certain uninformed traders tend to strategically act on noisy signals, and therefore, their trading can affect prices in a systematic way. These uninformed traders who are usually termed as positive feedback traders cause asset prices to deviate from fundamental values when they are unusually bullish or bearish. Since positive feedback trading adds additional risk to arbitrage activities implemented by informed traders, informed traders may therefore not take sufficiently large arbitrage positions to eliminate noise-driven price movements. Under certain circumstances, informed traders may expect price trends to continue in the short run because of 
positive feedback trading. Consequently, the sign of arbitrage positions taken by rational traders can be the opposite of what one needs to move asset prices towards fundamentals.

The ability to identify informed traders and noise traders is apparently valuable for predicting asset price movements. An accurate identification of trader types, however, requires timely position information that is usually illegitimate and at least costly in most financial markets. The COT reports provide a unique opportunity to legally trace timely trader positions in futures markets. The position information has been published weekly on Fridays since November 1992, relating to closing positions on the preceding Tuesdays taken by large speculators, large hedgers, and small traders. The investor sentiment based on the unique position information may allow for a more accurate identification of whether a specific type of traders are informed traders, or positive feedback traders, or liquidity traders, and thus improve investors' market timing ability. The appropriate corresponding timing strategy is to follow informed trader sentiment, act against positive feedback trader sentiment, and ignore liquidity trader sentiment.

Several extant studies investigated the values of various opinion-based sentiment indices for forecasting. Solt and Statman (1988) found no statistically significant relation between the sentiment of investment newsletter writers and subsequent stock returns. De Bondt (1993) found that individual investors surveyed by the American Association of Individual Investors (AAII) forecast future stock returns as though they expect continuations of past stock returns. Clarke and Statman (1998) shown that the Bullish Sentiment Index is hardly useful for forecasting future returns. In addition, they found that past returns and volatilities do strongly affect sentiment. More recently, Fisher and Statman (2000) studied the sentiments of three groups of investors small investors, newsletter writers, and Wall Street strategists. They found that the sentiments of both small investors and Wall Street strategists are reliable contrary indicators for future S\&P 
500 stock returns, but no statistically significant relation between the sentiment of newsletter writers and stock returns is uncovered.

The above studies on sentiment indices focused on equity markets. Sanders, Irwin, and Leuthold (1997) investigated return predictability of the Consensus Bullish Index in futures markets, and concluded that noise trader sentiment has little impact on futures prices. However, how useful is the unique and closely watched COT information has not gained any academic interest. This study aims to provide initial empirical evidence on whether and how the investor sentiment based on actual positions forecasts returns in futures markets. The S\&P 500 index futures market is chosen in this study because it is one of the most liquid futures markets in the world, representing over $90 \%$ of all US stock index futures trading.

Briese (1994), Arnold (1995), along with Apogee and other investment newsletters, argued that hedger sentiment may be a useful straight buying or selling indicator especially in the S\&P 500 index futures market, suggesting that hedgers in the market may be better informed. Our results, however, do not support this contention. We find that speculator sentiment provides a reliable straight buying or selling signal. Hedger sentiment is a weak contrary indicator, this is, investors are advised to go short when hedgers are turning bullish, and to go long when they are turning bearish. Small trader sentiment does not forecast future returns. To test these hypotheses, we first examine the relation between the level of sentiment by type of trader and subsequent futures returns, and then show whether the extreme levels and the combination of sentiment by type of trader provide stronger timing signals. 


\section{Level of Sentiment by Type of Trader and Futures Returns}

We obtain the weekly COT data over the period from January 1993 to March 2000 from Pinnacle Data Corporation, Webster, New York. To match the COT data, we collect Tuesday's S\&P 500 index futures trading volume and open interest. In addition, we collect daily S\&P 500 index futures opening, high, low, and settlement prices over the same sample period. These data come from Datastream International. The sample period is chosen because of the non-availability of weekly COT data prior to the end of 1992. Similarly to the COT index in the market place, we construct a sentiment index for a type of traders based on current net positions and historical extreme values. The sentiment index, SI, for a type of traders $i$ at week $t$ is

$$
S I_{i t}=\frac{N P_{i t}-\operatorname{Min}\left(N P_{i t}\right)}{\operatorname{Max}\left(N P_{i t}\right)-\operatorname{Min}\left(N P_{i t}\right)} \times 100,
$$

where $\mathrm{NP}_{\mathrm{it}}$ represents net positions taken by a type of traders $\mathrm{i}$ at week $\mathrm{t}$, $\mathrm{i}$ denotes large speculators, large hedgers, and small traders respectively, net position is defined as long open interest less short open interest, and $\max \left(\mathrm{NP}_{\mathrm{it}}\right)$ and $\min \left(\mathrm{NP}_{\mathrm{it}}\right)$ are the maximum and minimum net positions up to week $\mathrm{t}$ for a type of traders $\mathrm{i}^{3}$

Table 1 provides summary statistics for the sentiment indices of the three types of traders, and the contemporaneous relation between the sentiment by type of trader and S\&P 500 index futures returns. The average weekly futures returns over the sample period is 0.06 percent, while the average sentiment of large speculators, large hedgers, and small traders is 54.4 percent, 38.9 percent, and 62.1 percent respectively. From Table 1, it is apparent that the sentiments of the two

\footnotetext{
${ }^{3}$ We also use max and min net positions in a five-year moving window. The qualitative results remain largely unchanged. The advantage of using historical extreme values is to control for the frequency of the occurrence of zero or one sentiment index, which would affect our later regression results. In order to measure investor sentiment in 1993, we use the max and min net positions starting from 1990 calculated from the CFTC's bi-weekly COT reports.
} 
types of large traders do not move in the same direction. Higher level (bullishness) of speculator sentiment is often associated with lower level (bearishness) of hedger sentiment, and vice versa. Small trader sentiment appears to move more closely with speculator sentiment than with hedger sentiment. The correlation between speculator sentiment and hedger sentiment, the correlation between hedger sentiment and small trader sentiment, and the correlation between speculator sentiment and small trader sentiment are $-0.81,-0.74$, and 0.42 , respectively. Table 1 shows that the correlation between large speculator sentiment and returns, and the correlation between small trader sentiment and returns, are positive, although the magnitude of the correlation is smaller in the later case (0.03) than in the former case (0.1). However, the correlation between large hedger sentiment and futures returns is negative (-0.08). The sentiment indices of large speculators, large hedgers, and small traders are graphed in Figure 1. 
Figure 1. Sentiments of Large Speculators, Large Hedgers, and Small Traders in the S\&P 500 Stock Index Futures Market (1/1993 -3/2000)

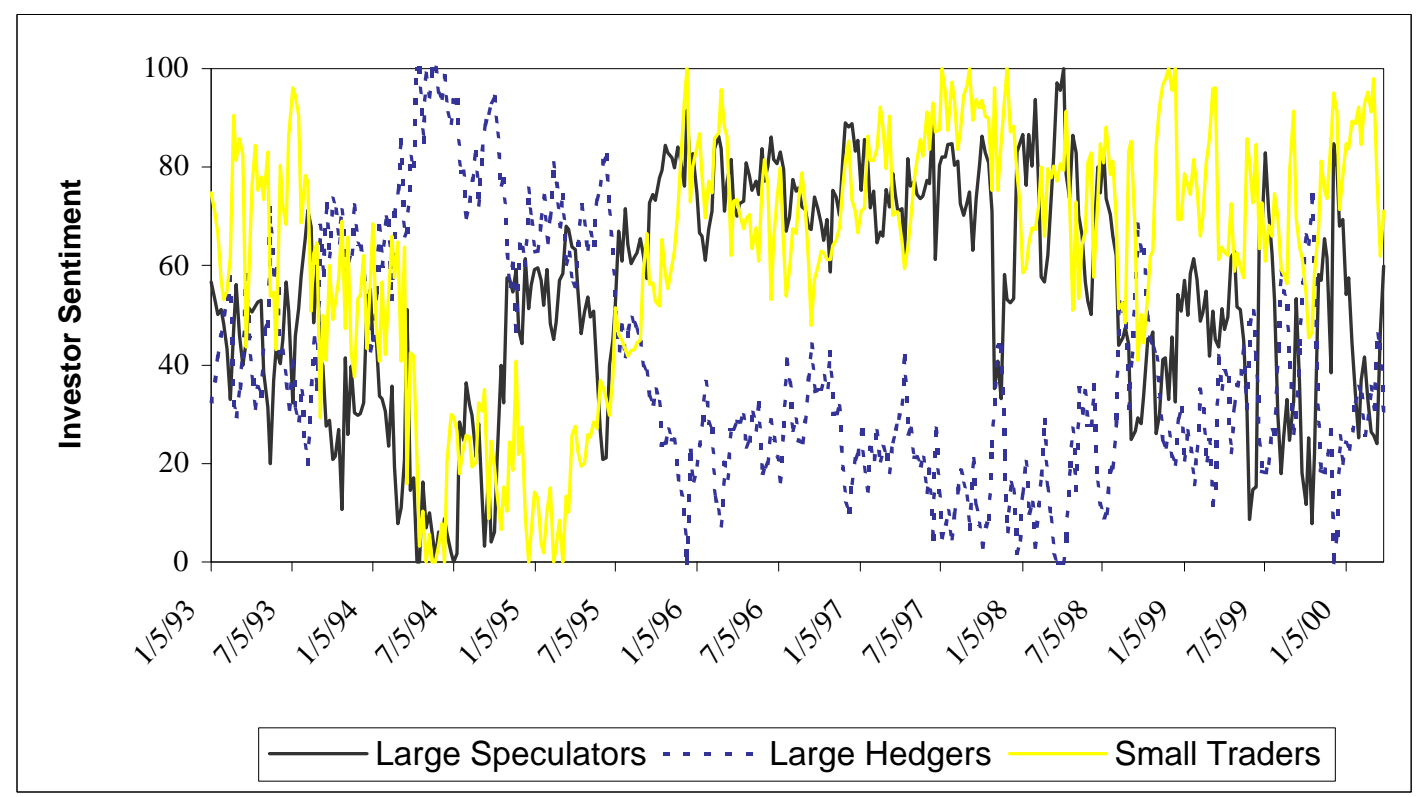

Table 1. Summary Statistics for the Sentiment by Type of Trader and Correlations between the Sentiment by Type of Trader and Futures Returns (\%) (1/1993 - 3/2000)

\begin{tabular}{lllll}
\hline & Returns & Large Speculator & Large Hedger & Small Trader \\
& & & & \\
\hline Mean & 0.063 & 54.40 & 39.79 & 62.12 \\
Median & 0.008 & 57.11 & 33.85 & 66.74 \\
St. Dev. & 0.981 & 22.95 & 23.92 & 19.25 \\
\hline \multicolumn{5}{l}{} \\
Correlation Matrix & & & \\
\hline Return & 1.00 & & & \\
Large Speculator & 0.10 & 1.00 & 1.00 & \\
Large Hedger & -0.08 & -0.81 & -0.74 & 1.00 \\
Small Trader & 0.03 & 0.42 & & \\
\hline
\end{tabular}


To see whether investor sentiment forecasts price continuations or reversals, following Clarke and Statman (1998) and Fisher and Statman (2000), we examine the relation between the level of sentiment by type of trader and holding-period returns in the subsequent nonoverlapping periods of 1 week, 2 weeks, 4 weeks, 6 weeks, and 8 weeks. ${ }^{4}$ The regression results are reported in Table 2. Panel A of Table 2 shows that speculator sentiment provides a reliable straight buying or selling signal. The relation between speculator sentiment and futures returns is positive and statistically significant at the $10 \%$ level (or higher) for all the periods. Consider the period of 4 weeks, an increase of 1 percentage point in the speculator sentiment is associated, on average, with a $0.03 \mathrm{pp}$ increase in the S\&P 500 futures returns in the subsequent 4 weeks.

Panel B of Table 2 shows that the relation between large hedger sentiment and futures returns is negative and statistically significant at the $10 \%$ level for all except the periods of 1 week and 8 weeks. For the period of 4 weeks, an increase of 1 percentage point in hedger sentiment is associated with a $0.02 \mathrm{pp}$ decrease in futures returns in the subsequent 4 weeks. However, the absolute magnitude of slope coefficient estimate for large hedgers in each forecasting period is smaller than that for large speculators. Moreover, the adjusted $\mathrm{R}^{2} \mathrm{~S}$ of the regressions are smaller than those for large speculators. This may suggest that large hedger sentiment is a weak contrary indicator.

Panel $\mathrm{C}$ of Table 2 indicates that the relation between small trader sentiment and futures returns is negative for the periods of 4 weeks and 6 weeks, but positive for the periods of 1 week, 2 weeks, and 8 weeks. However, none of the slope coefficient estimate is statistically significant,

\footnotetext{
${ }^{4}$ We initially included the forecasting periods of 12 weeks and 16 weeks. The regression results that are not reported here are not statistically significant for both types of large traders. Since the life cycle of a futures contract is 3 months, it may make sense if we consider only the short horizons (up to 8 weeks).
} 
and the adjusted $\mathrm{R}^{2} \mathrm{~S}$ of the regressions are close to zero. Therefore, it does not appear that small trader sentiment is a useful timing indicator. 
Table 2. The Relation between the Level of Sentiment by Type of Trader and S\&P 500 Futures Returns (\%) in Subsequent Nonoverlapping Periods (1/1993 - 3/2000)

Returns are measured as holding-period returns. t-statistics in parentheses are for the hypothesis that the coefficient is zero, computed using White (1980) heteroskedasticity consistent standard errors. A single asterisk indicates significance at the $10 \%$ level, a double asterisk denotes significance at the 5\% level, and a triple asterisk indicates significance at the $1 \%$ level or higher.

Panel A: Large Speculator

\begin{tabular}{llllll}
\hline & Intercept & Coefficient & $\begin{array}{l}\text { Durbin- } \\
\text { Watson }\end{array}$ & Adj. ${ }^{2}$ & No. of Obs. \\
\hline 1-week & $\begin{array}{l}-0.033 \\
(-1.77)^{*}\end{array}$ & $\begin{array}{l}0.007 \\
(2.26)^{* *}\end{array}$ & 1.69 & 0.03 & 188 \\
2-week & $\begin{array}{l}0.027 \\
(-0.78)\end{array}$ & $\begin{array}{l}0.011 \\
(1.76)^{*}\end{array}$ & 1.88 & 0.05 & 126 \\
4-week & $\begin{array}{l}0.081 \\
(-1.46)\end{array}$ & $\begin{array}{l}0.029 \\
(2.13)^{* *}\end{array}$ & 1.88 & 0.05 & 75 \\
6-week & $\begin{array}{l}0.171 \\
(-1.44)\end{array}$ & $\begin{array}{l}0.041 \\
(2.18)^{* *}\end{array}$ & 2.17 & 0.07 & 63 \\
8-week & -0.195 & $\begin{array}{l}0.049 \\
(1.95)^{*}\end{array}$ & 1.89 & 0.06 & 42 \\
\hline
\end{tabular}

Panel B: Large Hedger

\begin{tabular}{llllll}
\hline & Intercept & Coefficient & $\begin{array}{l}\text { Durbin- } \\
\text { Watson }\end{array}$ & Adj. $\mathbf{R}^{2}$ & No. of Obs. \\
\hline 1-week & $\begin{array}{l}0.024 \\
(1.85)^{*}\end{array}$ & $\begin{array}{l}-0.004 \\
(-1.08)\end{array}$ & 1.97 & 0.01 & 188 \\
2-week & $\begin{array}{l}0.037 \\
(1.34)\end{array}$ & $\begin{array}{l}-0.005 \\
(-1.69)^{*}\end{array}$ & 1.83 & 0.03 & 126 \\
4-week & $\begin{array}{l}0.085 \\
(1.96)^{* *}\end{array}$ & $\begin{array}{l}-0.014 \\
(-1.79)^{*}\end{array}$ & 1.94 & 0.04 & 75 \\
6-week & $\begin{array}{l}0.106 \\
(1.51)\end{array}$ & $\begin{array}{l}-0.015 \\
(-1.73)^{*}\end{array}$ & 2.05 & 0.03 & 63 \\
8-week & $\begin{array}{l}0.186 \\
(1.85)^{*}\end{array}$ & $\begin{array}{l}-0.031 \\
(-1.55)\end{array}$ & 1.61 & 0.02 & 42 \\
\hline
\end{tabular}


Panel C: Small Trader

\begin{tabular}{|c|c|c|c|c|c|}
\hline & Intercept & Coefficient & $\begin{array}{l}\text { Durbin- } \\
\text { Watson }\end{array}$ & Adj. $R^{2}$ & No. of Obs. \\
\hline 1-week & $\begin{array}{l}-0.001 \\
(0.05)\end{array}$ & $\begin{array}{l}0.000 \\
(0.25)\end{array}$ & 1.66 & -0.00 & 188 \\
\hline 2-week & $\begin{array}{l}-0.002 \\
(-0.05)\end{array}$ & $\begin{array}{l}0.003 \\
(0.53)\end{array}$ & 1.86 & 0.00 & 126 \\
\hline 4-week & $\begin{array}{l}-0.021 \\
(-0.36)\end{array}$ & $\begin{array}{l}-0.007 \\
(-0.19)\end{array}$ & 1.90 & -0.01 & 75 \\
\hline 6-week & $\begin{array}{l}0.024 \\
(0.24)\end{array}$ & $\begin{array}{l}-0.003 \\
(-0.23)\end{array}$ & 1.98 & 0.00 & 63 \\
\hline 8-week & $\begin{array}{l}-0.005 \\
(-0.46) \\
\end{array}$ & $\begin{array}{l}0.017 \\
(1.05) \\
\end{array}$ & 1.28 & 0.01 & 42 \\
\hline
\end{tabular}




\section{Extreme Levels of Large Trader Sentiments and Futures Returns}

We showed that there are statistically significant relations between large trader sentiments and subsequent returns in the S\&P 500 futures market. However, we have also noted that the economic significance of the relations may not be very strong. Form a practitioner's viewpoint, it is of importance to be able to identify a more reliable sentiment-based timing strategy. In this and the following sections, we search for more reliable and profitable timing strategies. As an extension of our previous findings, we would expect that the extreme levels of sentiments of the two types of large traders are stronger market-timing indicators. Specifically, extremely bullish speculator sentiment predicts higher future prices, while extremely bearish speculator sentiment forecasts lower future prices. Conversely, extremely bullish hedger sentiment predicts lower prices, while extremely bearish hedger sentiment forecasts higher prices. To test this conjecture, we sort the sentiments of large speculators and large hedgers based on extreme values into two groups: extremely bullish sentiment and extremely bearish sentiment. The extreme level of sentiment is defined as the sentiment index outside the range of $(25 \%, 75 \%)$. We then calculate the mean holding-period returns for each group in the subsequent periods of 1 week, 2 weeks, 4 weeks, 6 weeks, and 8 weeks. We use raw returns rather than abnormal returns in this analysis for two reasons. First, it may not make sense to use abnormal returns in futures markets. This is because futures trading requires no investment, and margin is regarded as performance bonds. Therefore, the expected return for holding a futures contract is virtually zero. ${ }^{5}$ Second, our objective is to show the divergent forecasts provided by the

\footnotetext{
${ }^{5}$ Compared to securities trading, the term 'margin' in futures trading has a different meaning and serves a different purpose. Rather than providing a down payment in equity markets, the margin required to buy or sell a futures contract is solely a deposit of good faith. In addition, margin can be deposited in marketable securities that continue to earn returns in equity or money markets. McCurdy and Morgan (1988) provided empirical evidence that the weekly futures rate follows a martingale.
} 
sentiments of different traders. That the sentiment by type of trader forecasts different patterns of subsequent raw returns may be sufficient for this purpose. The mean returns for each group in the subsequent periods are reported in Table 3. Also reported in Table 3 are z-statistics and Fstatistics. z-statistics are asymptotically distributed as $\mathrm{N}(0,1)$ and corrected for heteroskedasticity and autocorrelation based on Newey-West adjustment (1987), are for the hypothesis that the mean returns are zero. F-statistics are for the hypothesis that the mean returns for the two groups in each forecasting period are equal.

Panel A of Table 3 presents the mean returns for the group with extremely bullish sentiment (top 25 percent) and the group with extremely bearish sentiment (bottom 25 percent) for large speculators. As expected, the mean returns for the group with extremely bullish sentiment that represents the average returns for a timing strategy that follows extremely bullish speculator sentiment are positive and statistically significant at the $1 \%$ level. The mean returns for the group with extremely bearish sentiment are entirely negative, but statistically significant only for the periods of 6 weeks and 8 weeks. F tests reject the null hypothesis that the mean returns for the two groups are equal at the $5 \%$ level (or higher) for all the forecasting periods. The results for large hedgers are presented in Panel B of Table 3. Contrary to the hypothesis that extremely bullish hedger sentiment predicts negative returns, the mean returns for the group with extremely bullish hedger sentiment are positive for all except the period of 8 weeks, although not statistically significant. As predicted, the mean returns for the group with extremely bearish hedger sentiment are positive and significant for all except the period of 1 week. F tests reject the equality of mean returns of the two groups for all except the period of 1 week.

Two points regarding the forecasts provided by the extreme levels of sentiments of the two types of large traders are worth noting. First, the timing strategy that follows extremely 
bullish speculator sentiment persistently outperforms the strategy that follows extremely bearish speculator sentiment. On the other hand, the timing strategy that is contrary to extremely bearish hedger sentiment noticeably outperforms the strategy that is contrary to extremely bullish hedger sentiment. This result implies that the extreme level of large trader sentiment provides a more reliable buying signal than a selling signal. ${ }^{6}$ Second, the mean returns for the group with extremely bearish hedger sentiment for all the forecasting periods are persistently smaller than those for the group with extremely bullish speculator sentiment. The evidence is consistent with our previous result that hedger sentiment is a weak contrary indicator.

\footnotetext{
${ }^{6}$ It may be argued that the failure to generate a reliable selling signal based on sentiments of both types of large traders is likely due to the generally bull market over the sample period. In a bull market holding a long position, on average, generates positive returns, while holding a short position loses money. Thus, in a bull market traders may expect a positive return irrespective of trader types. However, this argument cannot explain the fact that extremely bearish hedger sentiment reliably forecasts positive returns. We will conduct robustness check on whether a simple trading strategy conditional on past returns would generate significant profits in the later analysis.
} 
Table 3. Extreme Levels of Large Trader Sentiments and Futures Returns (\%) in Subsequent Periods

Returns are measured as holding-period returns. The extreme sentiment is defined as the sentiment index outside the range of $(25 \%, 75 \%)$. The numbers in parentheses are z-statistics that are asymptotically $\mathrm{N}(0,1)$ under the null hypothesis that the relevant parameter is zero, and are corrected for heteroskedasticity and autocorrelation based on Newey-West adjustment (1987). F-test statistics are for the hypothesis that the mean returns for the groups in a forecasting period are equal. A single asterisk indicates significance at the $10 \%$ level, a double asterisk denotes significance at the 5\% level, and a triple asterisk indicates significance at the $1 \%$ level or higher.

Panel A: Large Speculator

\begin{tabular}{llllll}
\hline & 1-week & 2-week & 4-week & 6-week & 8-week \\
\hline Extremely & 0.233 & 0.328 & 0.922 & 1.284 & 1.380 \\
Bullish & $(2.94)^{* * *}$ & $(3.64)^{* * *}$ & $(4.25)^{* * *}$ & $(4.18)^{* * *}$ & $(4.04)^{* * *}$ \\
& & & & & \\
Extremely & -0.010 & -0.052 & -0.056 & -0.273 & -0.467 \\
Bearish & $(-0.57)$ & $(-0.49)$ & $(-0.87)$ & $(-2.40) * *$ & $(-1.75)^{*}$ \\
F-test & $5.79 * *$ & $10.31 * * *$ & $12.29 * * *$ & $17.62 * * *$ & $19.42 * * *$ \\
\hline
\end{tabular}

Panel B: Large Hedger

\begin{tabular}{llllll}
\hline & 1-week & 2-week & 4-week & 6-week & 8-week \\
\hline Extremely & 0.103 & 0.032 & 0.014 & 0.028 & -0.042 \\
Bullish & $(0.77)$ & $(0.43)$ & $(0.13)$ & $(0.24)$ & $(-0.28)$ \\
& & & & & \\
Extremely & 0.176 & 0.223 & 0.747 & 1.136 & 1.292 \\
Bearish & $(0.90)$ & $(1.68)^{*}$ & $(2.65)^{* * *}$ & $(3.24)^{* * *}$ & $(2.37)^{* *}$ \\
F-test & 0.54 & $2.87 *$ & $5.96^{* *}$ & $8.91^{* * *}$ & $16.35^{* * *}$ \\
\hline
\end{tabular}




\section{Combinations of Large Trader Sentiments and Futures Returns}

Our previous results indicated that the sentiments of both large speculators and large hedgers predict futures returns, but they provide opposite forecasts. Therefore, we would expect that combining the sentiments of the two types of large traders provides a more reliable markettiming signal. Two sets of hypotheses are formulated to test the usefulness of combining the sentiments of the two types of large traders for forecasting. First, bullish speculator sentiment together with bearish hedger sentiment predicts positive returns, whereas bearish speculator sentiment along with bullish hedger sentiment forecasts negative returns. Second, extremely bullish speculator sentiment together with extremely bearish hedger sentiment predicts positive returns, whereas extremely bearish speculator sentiment along with extremely bullish hedger sentiment predicts negative returns.

To test the first set of hypotheses, we sort the sentiments of large speculators and large hedgers based on the medians and form two groups: $\mathrm{H}$ and L. $\mathrm{H}$ represents the group with bullish speculator sentiment (above-the-median) together with bearish hedger sentiment (below-themedian). L represents the group with bearish speculator sentiment (below-the-median) together with bullish hedger sentiment (above-the-median). We then calculate the mean holding-period returns for $\mathrm{H}$ and $\mathrm{L}$ in the subsequent periods of 1 week, 2 weeks, 4 weeks, 6 weeks, and 8 weeks. The results are presented in Panel A of Table 4. As expected, the mean returns for $\mathrm{H}$ are positive and significant for all the subsequent periods. The mean returns for $\mathrm{L}$ are negative for all except the period of 2 weeks, although not statistically significant. F-tests reject the hypothesis that the mean returns for $\mathrm{H}$ equal those for $\mathrm{L}$ for all except the periods of 1 week and 2 weeks. Notice that the mean returns for $\mathrm{H}$ for all forecasting periods are less than those for the timing strategy that follows extremely bullish speculator sentiment. This suggests that combining the 
sentiments of the two types of large traders based on medians does not provide a stronger market-timing signal than does the extreme level of large speculator sentiment alone.

We test the second set of hypotheses by combining extreme levels of sentiments of large speculators and large hedgers. This procedure yields two groups: M and N. M represents the group with extremely bullish speculator sentiment (top 25 percent) along with extremely bearish hedger sentiment (bottom 25 percent). $\mathrm{N}$ represents the group with extremely bearish speculator sentiment (bottom 25 percent) along with extremely bullish hedger sentiment (top 25 percent). We calculate the mean returns for $\mathrm{M}$ and $\mathrm{N}$ in subsequent periods. The results are reported in Panel B of Table 4. As expected, the mean returns for $\mathrm{M}$ are positive and significant for all the periods. The mean returns for $\mathrm{N}$ are negative for all except the period of 6 weeks, but not statistically significant. $\mathrm{F}$ tests reject the equality of mean returns for $\mathrm{M}$ and $\mathrm{N}$ for all the periods.

It is noted that Group M appears to perform better than Group N, or the timing strategy that follows extremely bullish speculator sentiment, or the strategy that is contrary to extremely bearish hedger sentiment (with the exception of the period of 1 week). The economic significance of the mean returns for Group $\mathrm{M}$ can be better assessed by converting the holdingperiod returns to annualized returns. The annualized returns for Group $\mathrm{M}$ in the subsequent periods of 1 week, 2 weeks, 4 weeks, 6 weeks, and 8 weeks are 9.7\%, 9.3\%, 11.6\%, 11.9\%, and $10.7 \%$ respectively. ${ }^{7}$ Consistent with the previous result, our findings imply that combining the extreme levels of large trader sentiments generates the strongest buying signal (for the periods longer than 1 week). However, this may not necessarily provide a stronger selling signal than the timing strategy that follows extremely bearish speculator sentiment alone.

\footnotetext{
${ }^{7}$ The annualized return is calculated by first dividing the holding period returns by the number of periods (in weeks) and then multiplied by 52 . For example, the annualized return for the period of 4 weeks is $(0.892 \%) *(52 / 4)=11.6 \%$.
} 
Our findings from the examination of various timing strategies based on investor sentiment are generally consistent with the previous regression results, that is, large speculator sentiment provides a straight buying or selling signal, and large hedger sentiment is a contrary indicator. If speculator sentiment forecasts price continuations, large speculators in the S\&P 500 index futures market may be associated, on average, with superior forecasting ability. In contrast, large hedgers whose sentiment predicts price reversals are likely to be positive feedback traders who often overreact to nonfundamental information. Small traders may be motivated to trade for liquidity needs. Our result that large speculators tend to have superior forecasting power is consistent with the findings of Chang (1985) and Chang, Pinegar, and Schachter (1997) who examined broader futures markets. At first glance, the result is surprising because the S\&P 500 index futures market has apparently been dominated by large hedgers in either long or short positions. However, an examination of net futures positions reveals that large speculators are more concentrated on one side of the market than hedgers, which may explain the differential informativeness of trades of the two types of large traders. ${ }^{8}$

\footnotetext{
${ }^{8}$ The average long and short positions taken by large hedgers from January 1993-March 2000 accounted for 72\% and $66 \%$ of total open interest, and those by large speculators accounted for only $4 \%$ and $11 \%$ of total open interest. However, the average net positions of large speculators and large hedgers over the same sample period were 16,700 and 14,800 contracts (negative sign denotes a short position), respectively.
} 
Table 4. Combinations of Large Trader Sentiments and Futures Returns (\%) in Subsequent Periods

The numbers in parentheses are z-statistics that are asymptotically $\mathrm{N}(0,1)$ under the null hypothesis that the relevant parameter is zero, and are corrected for heteroskedasticity and autocorrelation based on Newey-West adjustment (1987). F-test statistics are for the hypothesis that the mean returns for the groups in a forecasting period are equal. A single asterisk indicates significance at the $10 \%$ level, a double asterisk denotes significance at the 5\% level, and a triple asterisk indicates significance at the $1 \%$ level.

Panel A: Combinations of Large Trader Sentiments and Futures Returns

$\mathrm{H}$ represents the group with above-the-median speculator sentiment together with below-themedian hedger sentiment. L represents the group with below-the-median speculator sentiment along with above-the-median hedger sentiment.

\begin{tabular}{|c|c|c|c|c|c|}
\hline & 1 week & 2-week & 4-week & 6-week & 8-week \\
\hline $\mathrm{H}$ & $\begin{array}{l}0.129 \\
(1.68)^{*}\end{array}$ & $\begin{array}{l}0.272 \\
(2.00)^{* *}\end{array}$ & $\begin{array}{l}0.661 \\
(3.28) * * *\end{array}$ & $\begin{array}{l}1.096 \\
(4.34)^{* * *}\end{array}$ & $\begin{array}{l}1.323 \\
(2.17) * *\end{array}$ \\
\hline $\mathrm{L}$ & $\begin{array}{l}-0.004 \\
(-0.06)\end{array}$ & $\begin{array}{l}0.003 \\
(0.03)\end{array}$ & $\begin{array}{l}-0.029 \\
(-0.18)\end{array}$ & $\begin{array}{l}-0.146 \\
(-0.78)\end{array}$ & $\begin{array}{l}-0.231 \\
(-1.12)\end{array}$ \\
\hline F-test & 1.38 & 2.53 & $7.36 * * *$ & $15.69 * * *$ & $27.65 * * *$ \\
\hline
\end{tabular}

Panel B: Combinations of Extreme Levels of Large Trader Sentiments and Futures Returns $(\%)$

M represents the group with extremely bullish speculator sentiment (top 25 percent) together with extremely bearish hedger sentiment (bottom 25 percent). $\mathrm{N}$ represents the group with extremely bearish speculator sentiment (bottom 25 percent) together with extremely bullish hedger sentiment (top 25 percent).

\begin{tabular}{rlllll}
\hline & 1 week & 2-week & 4-week & 6-week & 8-week \\
\hline $\mathrm{M}$ & 0.187 & 0.356 & 0.892 & 1.372 & 1.625 \\
& $(1.72)^{*}$ & $(2.05)^{* *}$ & $(2.98)^{* * *}$ & $(3.67)^{* * *}$ & $(2.23)^{* *}$ \\
$\mathrm{~N}$ & -0.020 & -0.003 & -0.004 & 0.001 & -0.096 \\
& $(-0.29)$ & $(-0.27)$ & $(-0.04)$ & $(0.00)$ & $(0.62)$ \\
& & & & & \\
F-test & $2.89 *$ & $2.96 *$ & $8.03 * * *$ & $12.17 * * *$ & $29.59 * * *$ \\
\hline
\end{tabular}




\section{Do Past Returns Forecast Future Returns?}

It is noted that in Tables 3 and 4 we used raw returns to evaluate the forecasts provided by the sentiment by type of trader. The results showed that the sentiments of both large speculators and large hedgers provide a more reliable buying signal than a selling signal. Put in other words, the correlations between the large trader sentiments and subsequent returns are only strong when those returns are positive. This leads us to suspect whether a simple strategy conditional on past returns would generate the same significant profits as the timing strategy based on investor sentiment. ${ }^{9}$ As a robustness check of our results, we regress futures returns in the subsequent nonoverlapping $\mathrm{K}$ periods on those in the previous $\mathrm{K}$ periods, where $\mathrm{K}=1,2,4$, 6, 8 weeks. The regression results are reported in Table 5.

The evidence suggests that it does not appear that a strategy conditional on past returns earns significant profits over any reasonable period of time in the S\&P 500 index futures market. The slope coefficient estimate is negative for the period of 4 weeks and positive for the other periods. However, none is statistically significant. Adjusted $\mathrm{R}^{2} \mathrm{~s}$ of the regressions are in the neighborhood of zero (the adjusted $\mathrm{R}^{2}$ of the regression for the period of 8 weeks is 0.02 , however, it is likely to be unreliable given that the regression has only 23 observations).

\footnotetext{
${ }^{9}$ We thank the referee for pointing out this possibility.
} 
Table 5. The Relation between Future Returns and Past Returns (1/1993 - 3/2000)

t-statistics in parentheses are for the hypothesis that the coefficient is zero, computed using White (1980) heteroskedasticity consistent standard errors. A single asterisk indicates significance at the $10 \%$ level, a double asterisk denotes significance at the $5 \%$ level, and a triple asterisk indicates significance at the $1 \%$ level or higher.

\begin{tabular}{llllll}
\hline & 1-week & 2-week & 4-week & 6-week & 8-week \\
\hline Intercept & -0.003 & 0.198 & 0.100 & 1.446 & 0.550 \\
& $(-0.03)$ & $(1.04)$ & $(0.32)$ & $(2.66)^{* *}$ & $(0.93)$ \\
Lagged & 0.017 & 0.004 & -0.065 & 0.019 & 0.157 \\
Returns & $(0.28)$ & $(0.84)$ & $(-0.47)$ & $(0.09)$ & $(1.53)$ \\
Durbin- & 1.86 & 2.04 & 1.66 & 1.65 & 1.67 \\
Watson & & & & & \\
Adj. $\mathbf{R}^{2}$ & 0.01 & -0.00 & -0.01 & 0.00 & 0.02 \\
No. of Obs. & 126 & 75 & 42 & 28 & 23 \\
\hline
\end{tabular}




\section{What Makes Traders Bullish?}

We have conjectured that large speculators are associated with superior forecasting ability, large hedgers may be positive feedback traders, and small traders are liquidity traders. The informativeness of trades by the three types of traders may explain the role of sentiment by type of trader for forecasting. Based on trader behavior in market microstructure models and noise trading theories, in this and the following sections we investigate the informativeness of trades by type of trader. This section examines how investor sentiment responds to past returns and volatilities that are regarded as two prominent factors affecting sentiment.

Pfleiderer (1984), Kyle (1985), Admati and Pfleiderer (1988), and De Long, Shleifer, Summers, and Waldmann $(1989,1990 \mathrm{a}, 1990 \mathrm{~b})$ argued that rational informed traders respond to private information. Therefore, past information, such as past returns and volatilities, should not significantly affect the sentiments of informed traders. However, uninformed traders are more likely to base their trading decisions on past information. High past return is likely to turn them more bullish, and high volatility may scare them into bearishness. To investigate whether past information makes traders more bullish or bearish, we regress the level of sentiment by type of trader on lagged sentiment and returns in previous nonoverlapping periods of 1 week, 2 weeks, 4 weeks, 6 weeks, and 8 weeks. The regression results are reported in Table 6 .

From Panel A of Table 6, it does not appear that past returns significantly affect large speculator sentiment except for the short horizon (1 week) for which the slope coefficient estimate is positive and statistically significant at the $10 \%$ level. This suggests that an increase of 1 percentage point in previous week returns is, on average, associated with $0.41 \mathrm{pp}$ increase in large speculator sentiment. The slope coefficient estimate is negative for the periods of 2 weeks, 6 weeks, and 8 weeks, and positive for the period of 4 weeks, but not statistically significant. 
Panel B of Table 6 reports the relation between the level of large hedger sentiment and past returns. The slope coefficient estimate is positive for all except the period of 8 weeks, although it is statistically significant only for the period of 6 weeks. Take the period of 6 weeks, an increase of $1 \mathrm{pp}$ in returns in the previous 6 weeks is associated with an increase of $1.5 \mathrm{pp}$ in current large hedger sentiment. Compared to those for large speculators, the magnitude of the slope coefficient estimate for large hedgers is, on average, larger. This may suggest that large hedgers base their trading decisions more on past returns than do large speculators. In conjunction with our previous results, it appears large hedgers' forecasts of price continuations for the periods of 2 weeks, 4 weeks, and 6 weeks are typically incorrect.

Surprisingly, Panel C of Table 6 shows that small trader sentiment is also not significantly affected by past returns except for the period of 8 weeks for which the slope coefficient is positive and statistically significant at the $5 \%$ level. In the later analysis, however, we confirm that they are typically discouraged by past volatilities.

The above analysis suggests that the relation between the level of sentiment by type of trader and past returns is generally not significant. As an additional check on whether investor sentiment is affected by past information, we regress changes in investor sentiment on lagged changes in sentiment, lagged returns and volatility for the three types of traders. We employ the volatility estimator developed by Garman and Klass (1980) that takes intra-day price changes into account. Following Daigler and Wiley (1999), the reduced form of Garman and Klass (1980) volatility estimator can be expressed as ${ }^{10}$

$$
\hat{\sigma}_{t}=\left\{0.5 \times\left[\ln \left(P_{t}, H / P_{t, L}\right)\right]^{2}-[2 \ln (2)-1]\left[\ln \left(P_{t, O} / P_{t, C}\right)\right]^{2}\right\}^{\frac{1}{2}},
$$

\footnotetext{
${ }^{10}$ We eliminate all cross terms in open/high/low/close prices. This will not significantly affect the coefficient estimates. As Daigler and Wiley (1999) pointed out, the correlation between these two volatility measures is above 0.95 , and the coefficients of regressions are very close each other.
} 
where $\mathrm{P}_{t, \mathrm{H}}, \mathrm{P}_{t, \mathrm{~L}}, \mathrm{P}_{t, \mathrm{O}}$, and $\mathrm{P}_{t, \mathrm{C}}$ are high, low, opening, settlement futures prices at date $\mathrm{t}$, respectively. The daily volatility estimates are averaged over the interval to match the weekly investor sentiment observations.

Table 7 records the regression results. The coefficient estimate for lagged volatility is negative for speculators and small traders, but positive for hedgers. However, it is statistically significant only for small traders. Consistent with the findings reported in Table 6, the coefficient estimate for lagged returns ( 1 week) is positive for all the three types of traders, although not statistically significant. The magnitude of the slope coefficient appears to be larger for small traders than for large traders. Our result may suggest that higher past returns likely make small traders more bullish than do large traders, and verse versa. Past volatility is unlikely to be the main factor driving the changes in sentiments of both speculators and hedgers. However, larger past volatility tends to scare off small traders. Our findings are broadly consistent with market microstructure models and nose trading theories in which informed traders (large speculators) react to private information, Uninformed traders (large hedgers and small traders) are more likely to base their trading decisions on past information. 
Table 6. The Relation between the Sentiment by Type of Trader and Past Returns (1/1993 $-3 / 2000$ )

t-statistics in parentheses are for the hypothesis that the coefficient is zero, computed using White (1980) heteroskedasticity consistent standard errors. A single asterisk indicates significance at the $10 \%$ level, a double asterisk denotes significance at the 5\% level, and a triple asterisk indicates significance at the $1 \%$ level or higher.

Panel A: Large Speculator

\begin{tabular}{|c|c|c|c|c|c|}
\hline & 1-week & 2-week & 4-week & 6-week & 8-week \\
\hline Intercept & $\begin{array}{l}10.338 \\
(4.11)^{* * *}\end{array}$ & $\begin{array}{l}14.28 \\
(3.89)^{* * *}\end{array}$ & $\begin{array}{l}8.958 \\
(2.81)^{* * *}\end{array}$ & $\begin{array}{l}10.468 \\
(2.62) * * *\end{array}$ & $\begin{array}{l}11.436 \\
(2.36) * *\end{array}$ \\
\hline Lagged & 0.808 & 0.738 & 0.780 & 0.741 & 0.733 \\
\hline Sentiment & $(19.04)^{* * *}$ & $(11.96)^{* * *}$ & $(11.67)^{* * *}$ & $(8.60) * * *$ & $(7.26) * * *$ \\
\hline Lagged & 0.411 & -0.017 & 0.014 & -0.831 & -1.071 \\
\hline Returns & $(1.69)^{*}$ & $(-0.02)$ & $(0.02)$ & $(-1.12)$ & $(-1.25)$ \\
\hline $\begin{array}{l}\text { Durbin- } \\
\text { Watson }\end{array}$ & 1.97 & 2.08 & 2.38 & 2.20 & 2.23 \\
\hline Adj. $R^{2}$ & 0.66 & 0.53 & 0.60 & 0.57 & 0.57 \\
\hline \multicolumn{6}{|c|}{ Panel B: Large Hedger } \\
\hline & 1-week & 2-week & 4-week & 6-week & 8-week \\
\hline Intercept & $\begin{array}{l}4.866 \\
(2.99) * * *\end{array}$ & $\begin{array}{l}7.295 \\
(2.87)^{* * *}\end{array}$ & $\begin{array}{l}12.678 \\
(2.99)^{* * *}\end{array}$ & $\begin{array}{l}15.133 \\
(2.73)^{* * *}\end{array}$ & $\begin{array}{l}16.037 \\
(2.23) * *\end{array}$ \\
\hline Lagged & 0.880 & 0.807 & 0.785 & 0.746 & 0.749 \\
\hline Sentiment & $(25.43)^{* * *}$ & $(14.92)^{* * *}$ & $(12.29)^{* * *}$ & $(9.16) * * *$ & $(6.93) * * *$ \\
\hline Lagged & 0.049 & 0.798 & 0.911 & 1.467 & -0.211 \\
\hline Returns & $(0.47)$ & $(0.89)$ & $(1.16)$ & $(2.05)^{* *}$ & $(-0.22)$ \\
\hline $\begin{array}{l}\text { Durbin- } \\
\text { Watson }\end{array}$ & 2.07 & 2.31 & 2.32 & 2.27 & 2.21 \\
\hline Adj. $R^{2}$ & 0.77 & 0.64 & 0.63 & 0.60 & 0.52 \\
\hline \multicolumn{6}{|c|}{ Panel C: Small Trader } \\
\hline & 1-week & 2-week & 4-week & 6-week & 8-week \\
\hline Intercept & $\begin{array}{l}8.722 \\
(3.48)^{* * *}\end{array}$ & $\begin{array}{l}11.219 \\
(3.17)^{* * *}\end{array}$ & $\begin{array}{l}0.167 * \\
(1.73)\end{array}$ & $\begin{array}{l}0.262 \\
(2.41)^{* *}\end{array}$ & $\begin{array}{l}-0.057 \\
(-0.43)\end{array}$ \\
\hline Lagged & 0.858 & 0.825 & -0.279 & -0.093 & -0.372 \\
\hline Sentiment & $(22.67)^{* * *}$ & $(15.72)^{* * *}$ & $(-2.41)^{* *}$ & $(-1.69)^{*}$ & $(-2.35) * *$ \\
\hline Lagged & 0.651 & -0.962 & 0.0354 & -0.048 & 0.112 \\
\hline Returns & $(0.92)$ & $(-1.11)$ & $(0.53)$ & $(-1.19)$ & $(2.47)^{* *}$ \\
\hline $\begin{array}{l}\text { Durbin- } \\
\text { Watson }\end{array}$ & 2.31 & 2.34 & 1.98 & 1.75 & 1.89 \\
\hline Adj. $R^{2}$ & 0.73 & 0.65 & 0.23 & 0.11 & 0.147 \\
\hline
\end{tabular}


Table 7. The Relation between Changes in Sentiment by Type of Trader, Past Returns and Volatility $(1 / 1993-3 / 2000)$

t-statistics in parentheses are for the hypothesis that the coefficient is zero, computed using White (1980) heteroskedasticity consistent standard errors. A single asterisk indicates significance at the $10 \%$ level, a double asterisk denotes significance at the 5\% level, and a triple asterisk indicates significance at the $1 \%$ level.

\begin{tabular}{llll}
\hline & Large Speculator & Large Hedger & Small Trader \\
\hline Intercept & 0.870 & -0.374 & -0.213 \\
& $(1.27)$ & $(-0.62)$ & $(0.28)$ \\
Lagged Changes & -0.165 & -0.106 & -0.268 \\
in Sentiment & $(-3.22)^{* * *}$ & $(-2.03)^{* *}$ & $(-5.36)^{* * *}$ \\
Lagged Return & 0.091 & 0.107 & 0.171 \\
& $(0.74)$ & $(1.09)$ & $(1.12)$ \\
Lagged Volatility & -0.258 & 0.481 & -0.372 \\
& $(-1.18)$ & $(0.93)$ & $(-1.86)^{*}$ \\
Durbin-Watson & 1.98 & 2.00 & 2.04 \\
Adj. $\mathrm{R}^{2}$ & 0.03 & 0.03 & 0.07 \\
\hline
\end{tabular}




\section{Absolute Changes in Sentiment by Type of Trader and Futures Volatility}

If our conjecture on the informativeness of trades by type of trader is correct, based on standard market microstructure models and noise trading theories, changes (in either direction) in hedger sentiment tends to move futures prices away from the intrinsic stock index values at contract maturity, thereby increasing volatility. Absolute changes in small trader sentiment that likely result from idiosyncratic wealth shocks or risk exposure adjustments may not significantly affect prices. The effect of absolute changes in speculator sentiment on prices is, however, influenced to a greater extent by how informed traders respond to positive feedback trading. Under normal circumstances, large speculators rationally counter the deviations of prices from fundamentals, and therefore, absolute changes in speculator sentiment stabilize the market. However, in the presence of positive feedback traders, large speculators may anticipate that it is more profitable to "jump on the bandwagon" than to "buck the trend". As a result, absolute changes in speculator sentiment may exaggerate price movements in short horizons.

As a final check of the informativeness of trades by the three types of traders, we examine the effect of absolute changes in sentiment by type of trader on futures prices. Specifically, we regress futures price volatility estimate on past volatilities, trading volume, open interest, and absolute changes in sentiment by type of trader. ${ }^{11}$ Past volatilities are included to account for the effect of volatility persistence. Trading volume and open interest are added to the regressions because there is extensive evidence on a positive relationship between trading volume and volatility, but a negative relationship between open interest and volatility. ${ }^{12}$ The

\footnotetext{
${ }^{11}$ Trading volume and open interest are in units of 10,000 contracts. Natural logarithmic trading volume and open interest are used in this study.

${ }^{12}$ Karpoff (1987) cited many studies that documented a positive relation between price volatility and trading volume in equity, currency and futures markets. Besembinder and Seguin $(1992,1993)$ documented both a positive relation between trading volume and volatility and a negative relation between open interest and volatility in various futures markets.
} 
coefficient estimate of absolute changes in sentiment can therefore be interpreted as the net effect of changes in sentiment on price volatility after controlling for the effect of trading volume and open interest. The daily volatility estimates are averaged over the interval to match the weekly sentiment observations. The regression results are reported in Table 8 .

Consistent with Bessembinder and Seguin (1992, 1993), the coefficient estimate for trading volume is positive and statistically significant, while that for open interest is negative. In line with the prediction of market microstructure models and noise trading theories, the coefficient estimate for absolute changes in speculator sentiment is negative, although not statistically significant. One possible interpretation for the result is that large speculators tend to, but not forcefully, trade to buck noise-driven price movements. It is also likely for them to buy or sell occasionally in anticipating positive feedback traders' reactions to their trades (De Long, Bradford, Shleifer, Summers, and Waldmann, 1990a and 1990b). As predicted, the coefficient estimate for absolute changes in hedger sentiment is positive and statistically significant at the $5 \%$ level. The change (in either direction) of 1 percentage point in hedger sentiment is associated, on average, with $0.12 \mathrm{pp}$ increase in daily volatility. The coefficient estimate for absolute changes in small trader sentiment is positive, but neither economically nor statistically significant. This result is as expected, indicating that small traders may be motivated to trade for liquidity needs, thus do not move asset prices in a systematic way. 
Table 8. The Relation between Absolute Changes in Sentiment by Type of Trader and Volatility (1/1993 - 3/2000)

t-statistics in parentheses are for the hypothesis that the coefficient is zero, computed using White (1980) heteroskedasticity consistent standard errors. A single asterisk indicates significance at the $10 \%$ level, a double asterisk denotes significance at the 5\% level, and a triple asterisk indicates significance at the $1 \%$ level or higher.

\begin{tabular}{llll}
\hline & Large Speculator & Large Hedger & Small Trader \\
& & & \\
\hline Intercept & 4.066 & 3.947 & 4.016 \\
& $(2.37)^{* *}$ & $(2.31)^{* *}$ & $(2.34)^{* *}$ \\
Lagged Volatility & 0.615 & 0.610 & 0.616 \\
& $(15.26)^{* * *}$ & $(15.23)^{* * *}$ & $(15.36)^{* * *}$ \\
Trading Volume & 0.536 & 0.531 & 0.529 \\
& $(4.41)^{* * *}$ & $(4.40)^{* * *}$ & $(4.37)^{* * *}$ \\
Open Interest & -1.389 & -1.368 & -1.373 \\
& $(-2.75) * * *$ & $(-2.72)^{* * *}$ & $(-2.71)^{* * *}$ \\
Change in Sentiment & -0.021 & 0.121 & 0.002 \\
& $(-0.42)$ & $(1.96)^{* *}$ & $(0.52)$ \\
Durbin-Watson & 2.02 & 2.01 & 2.02 \\
Adj. $\mathrm{R}^{2}$ & 0.39 & 0.42 & 0.39 \\
& & &
\end{tabular}




\section{Conclusions}

We studied the actual position-based sentiments of the three types of traders - large speculators, large hedgers, and small traders. We found that speculator sentiment is a price continuation indicator in the S\&P 500 index futures market. In contrast, hedger sentiment is a weak contrary indicator. Small trader sentiment does not have any value for forecasting. We also showed that extreme levels and the combination of extreme levels of sentiments of large speculators and large hedgers are more reliable timing indicators. Therefore, investors base their trading decisions on the extreme levels of large trader sentiments can generate significant profits over shorter horizons (up to 8 weeks). The evidence implies that large speculators may be associated with private information or superior forecasting ability in the market. Large hedgers behave like positive feedback traders who often overreact to nonfundamental information. Small traders are liquidity traders. The result that large speculators appear to have superior forecasting ability is consistent with the findings in Chang (1985) and Chang, Pinegar, and Schachter (1997).

To further check the robustness of our results and ascertain the informativeness of trades by type of trader, we examined the relation between past returns and future returns, the relation between the level of sentiment by type of trader and past returns, the relation between changes in sentiment by type of trader, past returns and past volatility, and the relation between absolute changes in sentiment by type of trader and price volatility. Based on trader behavior in the market microstructure literature and noise trading theories, the evidence broadly supported our conjecture on the informativeness of trades by the three types of traders that may explain the usefulness of sentiment by type of trader for forecasting.

Out study contributes to the literature in two ways. First, we provide initial empirical evidence on the usefulness of the sentiment index based on actual trader positions for forecasting 
S\&P 500 futures returns. Second, we test the informativeness of trades by different traders, and therefore, indirectly the market microstructure models and noise trading theories. Much work remains to be done in studying comprehensively the determinants of sentiments of the three types of traders and the return predictability of the sentiment index in other futures markets. 


\section{References:}

Admati, Anat R., and Paul Pfleiderer. 1988. "A Theory of Intraday Patterns: Volume and Price Variability." Review of Financial Studies, vol. 1, no. 1 (Spring): 3-40.

Arnold, Curtis. 1995. PPS Trading System. Irwin Publishing.

Bessembinder, Hendrik, and Paul J. Seguin. 1992. "Futures-Trading Activity and Stock Piece Volatility." Journal of Finance, vol. 47, no. 5 (December): 2015-2034.

Bessembinder, Hendrik, and Paul J. Seguin. 1993. "Price Volatility, Trading Volume, and Market Depth: Evidence from Futures Markets." Journal of Financial and Quantitative Analysis, vol. 28, no.1 (March): 21-39.

Briese, Stephen E. "Illuminating Data: Commitments of Traders Report Can Disclose Promise, Perils in the Market." Barron's, May 2, 1994.

Chang, Eric C. 1985. "Returns to Speculators and the Theory of Normal Backwardation." Journal of Finance, vol. 40, no.1 (March): 193-208.

Change, Eric C., J. Michael Pingenar, Barry Schachter. 1997. "Interday Variations in Volume, Variance and Participation of Large Speculators." Journal of Banking and Finance, vol. 21: 797810.

Clarke, Roger G., and Meir Statman. 1998. "Bullish or Bearish." Financial Analysts Journal, vol. 54, no. 6 (May/June): 63-72.

Daigler, Robert T. and Marilyn K. Wiley. 1998. "The Impact of Trader Type on the Futures Volatility-Volume Relation.” Journal of Finance, vol. 54 (December): 2297-2316.

De Bondt, Werner. 1993. "Betting on Trends: Intuitive Forecasts of Financial Risk and Returns." International Journal of Forecasting, vol. 9, no. 3 (November): 355-371.

De Long, J. Bradford, Andrei Shleifer, Lawrence H. Summers, and Robert J. Waldmann. 1989. "The Size and Incidence of the Losses from Noise Trading." Journal of Finance, vol. 44, no. 3 (July): 681-696.

De Long, J. Bradford, Andrei Shleifer, Lawrence H. Summers, and Robert J. Waldmann. 1990a. "Noise Trader Risk in Financial Markets." Journal of Political Economy, vol. 98, no. 4 (August): 703-738.

De Long, J. Bradford, Andrei Shleifer, Lawrence H. Summers, and Robert J. Waldmann. 1990b. "Positive Feedback Investment Strategies and Destabilizing Rational Speculation." Journal of Finance, vol. 45, no. 2 (June): 379-396. 
Fisher, Kenneth L., and Meir Statman. 2000. "Investor Sentiment and Stock Returns." Financial Analysts Journal, vol. 56, no. 2 (March/April): 16-23.

Garman, M. B., and M. J. Klass. 1980. "On the Estimation of Security Price Volatilities from Historical Data.” Journal of Business, vol.53, no.1 (January): 67-78.

Karpoff, J. M. 1987. "The Relation between Price Changes and Volume: A Survey." Journal of Financial and Quantitative Analysis, vol. 22 (March): 109-126.

Kyle, Albert S. 1985. "Continuous Auctions and Insider Trading." Econometrica, vol. 47, no.6 (November): 1315-1336.

McCurdy, T. H., and I. Morgan. 1988. "Testing the Martingale Hypothesis in Deutsche Mark Futures with Models Specifying the Form of Heteroskedasticity." Journal of Applied Econometrics, vol. 3 (April - June): 187-202.

Newey, Whitney K., and Kenneth D. West. 1987. "A Simple, Positive Semi-Definite, Heteroskedasticity and Autocorrelation Consistent Covariance Matrix." Econometrica, vol. 55, no.3 (May): 703-708.

Sanders, Dwight, R., Scott H. Irwin, and Raymond M. Leuthold. 1997. "Noise Traders, Market Sentiment, and Futures Price Behavior." Working Paper. University of Illinois at UrbanaChampaign.

Schwert, William, G. 1989. "Stock Volatility and the Crash of 87." Review of Financial Studies, vol. 3, no. 1 (Autumn): 77-102.

Solt, Michael E., and Meir Statman. 1988. "How Useful Is the Sentiment Index?" Financial Analysts Journal, vol. 44, no. 5 (September/October): 45-55.

White, H. 1980. "A Heteroskedasticity-Consistent Covariance Matrix Estimator and A Direct Test for Heteroskedasticity." Econometrica, vol. 48, no. 4 (May): 817-838. 